\title{
VENERABILI FRATRI NOSTRO CAROLO CARDINALI WOJTYŁA ARCHIEPISCOPO CRACOVIENSI
}

Sextum saeculum expletum ab ortu Hedvigis, Reginae Poloniae, Praesulibus, clero, fidelibus istius regionis opportunitatem praebet egregiae eiusdem mulieris memoriam celebrandi ab eaque documenta sumendi ad vitam, quae hac agitur aetate, attinentia.

Re quidem vera Regina illa sat brevi tempore, quo in terra degit, virtutibus colendis assidue institit, religionem catholicam propagavit et constabilivit, Facultatem Theologicam Cracoviensem condidit, opera caritatis et socialis provectionis excitavit, ut praecipua eius benefacta commemoremus. Cultus igitur ut Beatae ab immemorabili ei praestatur, de quo confirmando iudicium est apud Sedem Apostolicam institutum.

Sollemnia, ad memoriam lectissimae huius mulieris indicta, in tempus feliciter incidunt, quod Anno Sacro in Ecclesiis localibus celebrando tribuitur, et appropinquante iam universali Jubileo, Romae ad limina Apostolorum, in catholicae unitatis sede, agendo.

Vita interior, purificatio animi, reconciliatio cum Deo et cum fratribus: en nota argumenta, religiosis hisce celebritatibus proposita, quae vitam uniuscuiusque ac coetuum intime tangunt. Non equidem dubitamus, quin tu, Venerabilis Frater Noster, quo es studio pastorali, ceterique Pastores Poloniae operam detis, ut hoc magni momenti negotium spirituale greges vestri persentiant et in vitae usum traducant.

Hedvigis Regina, quemadmodum significavimus, plurimum est annisa, ut religionis catholicae fines proferrentur: haec etiam causa, scilicet evangelizatio - ut semper, ita et hac aetate ac quidem impensius - est cordi Ecclesiae; quin immo, ut notum est, proximo conventui Synodi Episcoporum ut argumentum pertractandum exhibebitur. Numquam enim oblivisci licet haec gravia verba Concilii Oecumenici Vaticani II: „In praesenti autem rerum ordine, ex quo nova exsurgit humanitatis con- 
dicio, Ecclesia, sal terrae et lux mundi (cf. Mt. 5, 13-14), urgentius vocatur ad omnem creaturam salvandam et renovandam, ut omnia in Christo instaurentur et in Ipso homines unam familiam unumque populum Dei constituant (Decr. „Ad gentes divinitus”, 1). Omnes igitur, etiam laici, impelli se sentiant, ut ad hanc causam vere apostolicam eo, quo fieri possit, modo efficaciter conferant.

Non necesse habemus opera eo pertinentia, ut aerumnae subleventur, egestati consulatur, auferantur iniustitiae, iterum inculcare: etenim ,hoc dilectionis signo Ecclesia oportet dignoscatur, quae, dum gaudet de aliorum inceptis, caritatis opera ut suum officium et ius, quod abalienari nequit, vindicat” (cf. Conc. Oec. Vat. II, Decr. „Apostolicam actuositatem", 8).

Ipsum vero tempus sacrum - Annum Sanctum dicimus - catholicos admonet, ut geminent nisus, quibus maximo dilectionis mandato Dominico satisfiat.

Vota denique facientes, ut haec pia celebratio in verum religionis vertat profectum, tibi, Venerabilis Frater, ceteris Poloniae Praesulibus, sacerdotibus, religiosis, Christifidelibus, illius participibus, Benedctionem Apostolicam superni roboris et solacii auspicem Nostraeque caritatis testem, libentissime impertimus.

Ex Aedibus Vaticanis, die $\mathrm{X}$ mensis Maii, anno MCMLXXIV, Pontificatus Nostri undecimo.

L.S.

(一) Paulus PP. VI. 